\title{
Simultaneous Determination of Dexamethasone, Ondansetron, Granisetron, Tropisetron, and Azasetron in Infusion Samples by HPLC with DAD Detection
}

\author{
Fu-chao Chen, ${ }^{1}$ Lin-hai Wang, ${ }^{2}$ Jun Guo, ${ }^{3}$ Xiao-ya Shi, ${ }^{1}$ and Bao-xia Fang ${ }^{1}$ \\ ${ }^{1}$ Department of Pharmacy, Dongfeng Hospital, Hubei University of Medicine, Shiyan, Hubei 442008, China \\ ${ }^{2}$ Department of Pharmacy, Renmin Hospital, Hubei University of Medicine, Shiyan, Hubei 442000, China \\ ${ }^{3}$ Department of Oncology, Dongfeng Hospital, Hubei University of Medicine, Shiyan, Hubei 442008, China
}

Correspondence should be addressed to Bao-xia Fang; fbx-811105@163.com

Received 21 October 2016; Accepted 19 December 2016; Published 11 January 2017

Academic Editor: Chih-Ching Huang

Copyright (C) 2017 Fu-chao Chen et al. This is an open access article distributed under the Creative Commons Attribution License, which permits unrestricted use, distribution, and reproduction in any medium, provided the original work is properly cited.

A simple and rapid high-performance liquid chromatography with diode array detector (HPLC-DAD) method has been developed and validated for simultaneous quantification of five antiemetic agents in infusion samples: dexamethasone, ondansetron, granisetron, tropisetron, and azasetron. The chromatographic separation was achieved on a Phenomenex $\mathrm{C}_{18}$ column (4.6 mm $\times 150 \mathrm{~mm}, 5 \mu \mathrm{m})$ using acetonitrile- $50 \mathrm{mM} \mathrm{KH}_{2} \mathrm{PO}_{4}$ buffer-triethylamine $(25: 74: 1 ; \mathrm{v} / \mathrm{v} ; \mathrm{pH} 4.0)$. Flow rate was $1.0 \mathrm{~mL} / \mathrm{min}$ with a column temperature of $30^{\circ} \mathrm{C}$. Validation of the method was made in terms of specificity, linearity, accuracy, and intra- and interday precision, as well as quantification and detection limits. The developed method can be used in the laboratory to routinely quantify dexamethasone, ondansetron, granisetron, tropisetron, and azasetron simultaneously and to evaluate the physicochemical stability of referred drugs in mixtures for endovenous use.

\section{Introduction}

Dexamethasone (DEX) (Figure 1(a)), a synthetic corticosteroid, has long been used as antiemetic agent in patients undergoing cancer chemotherapy $[1,2]$, being effective for both acute and delayed nausea and vomiting. Selective 5hydroxytryptamine type $3\left(5-\mathrm{HT}_{3}\right)$ receptor antagonists, including ondansetron (OND) (Figure 1(b)), granisetron (GRA) (Figure 1(c)), tropisetron (TRO) (Figure 1(d)), and azasetron (AZA) (Figure 1(e)), are effective and potent antiemetic drugs which are recommended by clinical practice guidelines for patients undergoing surgery and cancer chemotherapy [3-6]. Literature survey has revealed that coadministration of antiemetics from different classes could be a more effective antiemetic treatment modality, and DEX is a standard component of antiemetic combination regimens with $5-\mathrm{HT}_{3}$ antagonists [3,7-10]. Hence, mixtures of 5- $\mathrm{HT}_{3}$ receptor antagonists, alone or in combination with DEX, are often used in clinical practice to relieve chemotherapy induced nausea and vomiting. However, there are no commercially available such drug mixtures, and they must be prepared in the hospital pharmacy departments for clinical use.

From the literature survey it is evident that various analytical methods were available for the determination of DEX, OND, GRA, TRO, and AZA with other combinations by using high-performance liquid chromatography (HPLC) [11-31]. No method has been reported in the literature for simultaneous estimation of DEX, OND, GRA, TRO, and AZA in infusion samples. Hence, the objective of the current study was to develop and validate a simple, rapid, accurate, and precise HPLC method for simultaneous estimation of DEX, OND, GRA, TRO, and AZA in infusion samples.

\section{Experimental}

2.1. Chemicals and Reagents. The working standards of DEX sodium phosphate, OND hydrochloride, GRA hydrochloride, TRO hydrochloride, and AZA hydrochloride were purchased from the National Institutes for Food and Drug Control (Beijing, China) and stored at $4^{\circ} \mathrm{C}$. The pharmaceutical 


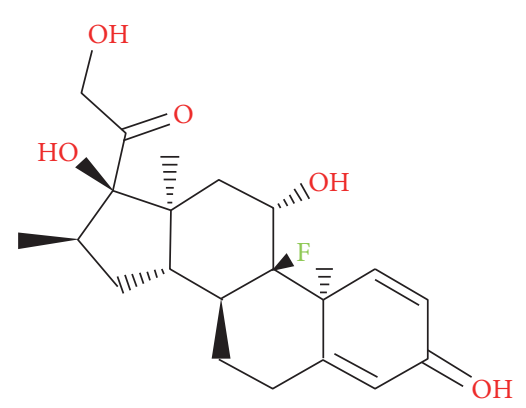

(a)

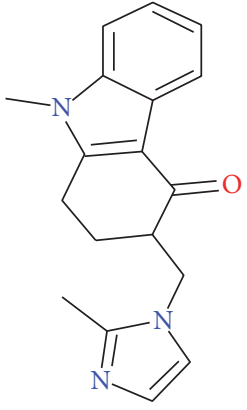

(b)

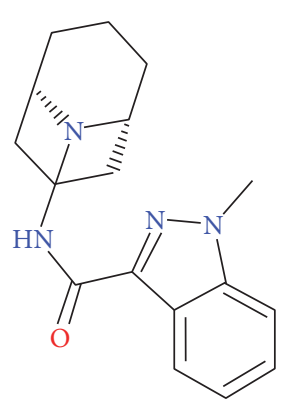

(c)<smiles>CN1[C@H]2CC[C@@H]1C[C@@H](OC(=O)c1c[nH]c3ccccc13)C2</smiles>

(d)

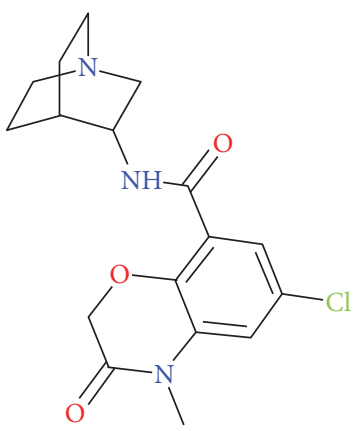

(e)

Figure 1: Chemical structure of DEX (a), OND (b), GRA (c), TRO (d), and AZA (e).

formulations used in this study were DEX sodium phosphate injection $5 \mathrm{mg} / 1 \mathrm{~mL}$ (Cisen Pharmaceutical Co., Ltd., Shandong, China), OND hydrochloride injection $4 \mathrm{mg} / 2 \mathrm{~mL}$ (Qilu Pharmaceutical Co., Ltd., Shandong, China), GRA hydrochloride injection $3 \mathrm{mg} / 3 \mathrm{~mL}$ (Cinkate Pharmaceutical Corporation, Suzhou, China), TRO hydrochloride injection $5 \mathrm{mg} / 1 \mathrm{~mL}$ (Qilu Pharmaceutical Co., Ltd., Shandong, China), and AZA hydrochloride injection $10 \mathrm{mg} / 2 \mathrm{~mL}$ (Wanma Pharmaceutical Co., Ltd., Zhejiang, China). The solution of $0.9 \%$ $\mathrm{NaCl}$ used to prepare the sample mixtures was from Kelun Pharmaceutical Co., Ltd. (Sichuan, China). Potassium dihydrogen phosphate $\mathrm{KH}_{2} \mathrm{PO}_{4}$, triethylamine, and phosphoric acid of AR Grade were obtained from Xilong Chemical Ltd. (Guangdong, China). HPLC grade acetonitrile was purchased from Fisher Scientific International (St Louis, MO, USA). Ultrapure water was purified using a Milli-Q system (Millipore, Bedford, MA, USA).

2.2. HPLC Instrumentation and Chromatographic Conditions. An UltiMate ${ }^{\circledR} 3000$ standard high pressure liquid chromatographic instrument (Dionex, Germany) composed of an UltiMate 3000 quaternary gradient pump, an ASI-100 autosampler, a TCC-100 thermostat column oven, and an ultraviolet detector (DAD) was employed in the study. Data acquisition was carried out using Chromeleon ${ }^{\circledR}$ software. Chromatographic analyses were performed on a Phenomenex $\mathrm{C}_{18}$ column $(4.6 \mathrm{~mm} \times 150 \mathrm{~mm}, 5 \mu \mathrm{m})$ and using the mobile phase of acetonitrile- $50 \mathrm{mM} \mathrm{KH} \mathrm{KO}_{4}$ buffer-triethylamine (25: $74: 1 ; \mathrm{pH}$ adjusted to 4.0 using diluted phosphoric acid). The mobile phase was prepared daily and filtered through a $0.22 \mu \mathrm{m}$ membrane filter (Millipore Corp., USA). The flow rate of the mobile phase was kept at $1.0 \mathrm{~mL} / \mathrm{min}$. The selected detection wavelengths for DEX, OND, GRA, TRO, and AZA were $241 \mathrm{~nm}, 310 \mathrm{~nm}, 302 \mathrm{~nm}, 285 \mathrm{~nm}$, and $302 \mathrm{~nm}$, respectively. The assay was performed at $30^{\circ} \mathrm{C}$ and injection volume was $20 \mu \mathrm{L}$.

2.3. Preparation of Stock and Working Solutions. We accurately weighed and transferred $20 \mathrm{mg}$ of DEX sodium phosphate, $16 \mathrm{mg}$ of OND hydrochloride, $12 \mathrm{mg}$ of GRA hydrochloride, $10 \mathrm{mg}$ of TRO hydrochloride, and $20 \mathrm{mg}$ of AZA hydrochloride working standard into a $100 \mathrm{~mL}$ volumetric flask. We added about $70 \mathrm{~mL}$ of deionised water and used sonication for dissolving completely and made volume up to the mark with the same solvent to obtain the final concentration of $0.2 \mathrm{mg} / \mathrm{mL}$ of DEX sodium phosphate, $0.16 \mathrm{mg} / \mathrm{mL}$ of OND hydrochloride, $0.12 \mathrm{mg} / \mathrm{mL}$ of GRA hydrochloride, $0.1 \mathrm{mg} / \mathrm{mL}$ of TRO hydrochloride, and $0.2 \mathrm{mg} / \mathrm{mL}$ of AZA hydrochloride, respectively. The solutions were kept at $-20^{\circ} \mathrm{C}$ until use. Fresh working standard solutions were prepared by diluting the stock solution with deionised water to the required concentrations before use.

2.4. Preparation of Infusion Samples. In order to mimic a concentration range relevant to clinical practice and the conditions commonly occurring in hospitals, four sample infusion solutions were prepared under aseptic conditions in laminar flow hoods.

Solution 1. $2 \mathrm{~mL}(10 \mathrm{mg})$ DEX sodium phosphate injectable solution and $4 \mathrm{~mL}(8 \mathrm{mg})$ OND hydrochloride injectable solution were transferred to a $100 \mathrm{~mL}$ polyolefin bags and filled with $0.9 \%$ sodium chloride injection. 
Solution 2. $2 \mathrm{~mL}(10 \mathrm{mg})$ DEX sodium phosphate injectable solution and $3 \mathrm{~mL}$ ( $3 \mathrm{mg}$ ) GRA hydrochloride injectable solution were transferred to a $100 \mathrm{~mL}$ polyolefin bags and filled with $0.9 \%$ sodium chloride injection.

Solution 3. $2 \mathrm{~mL}(10 \mathrm{mg})$ DEX sodium phosphate injectable solution and $1 \mathrm{~mL}(5 \mathrm{mg})$ TRO hydrochloride injectable solution were transferred to a $100 \mathrm{~mL}$ polyolefin bags and filled with $0.9 \%$ sodium chloride injection.

Solution 4. $2 \mathrm{~mL}$ (10 mg) AZA hydrochloride injectable solution was transferred to a $100 \mathrm{~mL}$ polyolefin bags and filled with $0.9 \%$ sodium chloride injection.

2.5. Validation of the Method. The developed analytical method was subjected to validation with respect to various parameters such as linearity, intra- and interday precision, accuracy, limit of quantification (LOQ), limit of detection (LOD), and reproducibility for each analyte.

\subsection{Physicochemical Stability Study of the Infusion Samples.} The compatibility and stability studies of the infusion samples were performed at $25 \pm 0.5^{\circ} \mathrm{C}$; all the solutions were protected from light exposure and checked at predetermined times: 0 , $2,4,8,24$, and 48 hours. At the specified times, the infusion samples were examined for the changes in appearance and the $\mathrm{pH}$ value of the mixture was also determined in a digital Crison phs-3c pH meter. Moreover, the concentrations of the drugs were determined at each analysis by the above described HPLC-DAD method. In the concentrations' analysis, $2 \mathrm{~mL}$ samples were collected from each polyolefin bag and were diluted 1:5 in deionised water before injection into HPLC system so as to be within the range covered by the calibration curves.

\section{Results and Discussion}

3.1. Optimization of Chromatographic Conditions. The present study is aimed at developing a chromatographic system capable of eluting the individual drugs, permitting their separation and simultaneous determination in infusion solutions. On the basis of the literature consulted [11-31], an acidic aqueous medium and acetonitrile were selected to start the optimization of mobile phase composition. Trials showed that an acidic mobile phase with reverse phase $\mathrm{C}_{18}$ column gives symmetric and sharp peaks. The best resolution and analysis time was obtained through isocratic elution using a mobile phase consisting of acetonitrile- $50 \mathrm{mM}$ $\mathrm{KH}_{2} \mathrm{PO}_{4}$ buffer-triethylamine $(25: 74: 1 ; \mathrm{v} / \mathrm{v} ; \mathrm{pH} 4.0)$ at a flow rate of $1.0 \mathrm{~mL} / \mathrm{min}$. Buffer $\mathrm{pH}$ was evaluated in the range from 2.0 to 6.0 , and good resolution and peak shapes were achieved at $\mathrm{pH}$ 4.0. Figure 2 displays representative HPLC profiles of mixtures detected at $241 \mathrm{~nm}$ for the five components. Under these chromatographic conditions, the average retention time for DEX sodium phosphate, OND hydrochloride, GRA hydrochloride, TRO hydrochloride, and AZA hydrochloride was found to be 10.72 , 8.12, 5.97, 7.10, and $4.55 \mathrm{~min}$, respectively. DAD was used because it has

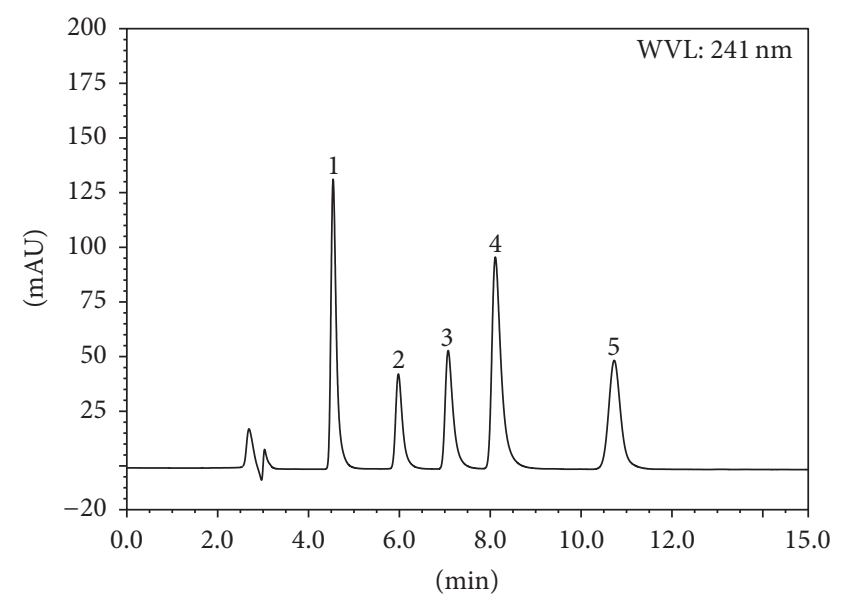

FIgURE 2: HPLC chromatograms of AZA (1), GRA (2), TRO (3), OND (4), and DEX (5).

advantages over conventional UV detection. It enables peak purity to be checked and simultaneous recording at the wavelength of maximum absorbance. The absorption maximum of DEX sodium phosphate, OND hydrochloride, GRA hydrochloride, TRO hydrochloride, and AZA hydrochloride at $241,310,302,285$, and $302 \mathrm{~nm}$ was selected for detection.

3.2. Linearity, Limit of Detection (LOD), and Limit of Quantitation (LOQ). Linearity was performed by preparing mixed standard solutions of DEX sodium phosphate, OND hydrochloride, GRA hydrochloride, TRO hydrochloride, and AZA hydrochloride at six concentration levels. The linearity of detector response for DEX sodium phosphate, OND hydrochloride, GRA hydrochloride, TRO hydrochloride, and AZA hydrochloride was demonstrated by prepared solutions of over the concentration range of $1.0-100.0 \mu \mathrm{g} / \mathrm{mL}$, $2.0-80.0 \mu \mathrm{g} / \mathrm{mL}, 1.2-36.0 \mu \mathrm{g} / \mathrm{mL}, 1.0-50.0 \mu \mathrm{g} / \mathrm{mL}$, and $2.0-$ $100.0 \mu \mathrm{g} / \mathrm{mL}$, respectively. The peak area ratio of each sample against respective concentration of five antiemetic agents was found to be linear. The correlation coefficient for all five antiemetic agents was greater than 0.998. Linearity results were presented in Table 1. The LOD and LOQ for five antiemetic agents were determined based on the standards/baseline signal-to-noise $(S / N)$ ratio. Dilutions and injections of DEX sodium phosphate, OND hydrochloride, GRA hydrochloride, TRO hydrochloride, and AZA hydrochloride standards were then made until an HPLC chromatograph showed that the three-peak height reached an $S / N$ of approximately $10: 1$ and 3:1 for LOQ and LOD solutions, respectively. The LOD and LOQ for both drugs were determined and shown in Table 1.

3.3. Precision. The precision (RSD) of the method was determined as intraday precision and intermediate precision. Intraday precision was estimated by assaying quality control samples at three concentration levels (1.0, 20.0, and $40.0 \mu \mathrm{g} / \mathrm{mL}$ for DEX sodium phosphate; 2.0, 16.0, and $32.0 \mu \mathrm{g} / \mathrm{mL}$ for OND hydrochloride; $1.2,6.0$, and $12.0 \mu \mathrm{g} / \mathrm{mL}$ for GRA hydrochloride; $1.0,10.0$, and $20.0 \mu \mathrm{g} / \mathrm{mL}$ for TRO 
TABLE 1: System suitability parameters for DEX, OND, GRA, TRO, and AZA.

\begin{tabular}{|c|c|c|c|c|c|}
\hline Analytical parameter & DEX & OND & GRA & TRO & $\mathrm{AZA}$ \\
\hline Detection wavelength (nm) & 241 & 310 & 302 & 285 & 302 \\
\hline Retention time (min) & 10.72 & 8.12 & 5.97 & 7.10 & 4.55 \\
\hline Theoretical plate $($ mean \pm SD) & $8567 \pm 129$ & $9476 \pm 98$ & $9075 \pm 104$ & $9593 \pm 115$ & $8445 \pm 112$ \\
\hline Linear range $(\mathrm{mg} / \mathrm{L})$ & $1.0-100.0$ & $2.0-80.0$ & $1.2-36.0$ & $1.0-50.0$ & $2.0-100.0$ \\
\hline Linear equation & $Y=0.7519 X-0.1208$ & $Y=1.5213 X-6.444$ & $Y=0.7563 X+0.3852$ & $Y=0.6965 X+0.7363$ & $Y=0.1918 X+0.1513$ \\
\hline Correlation coefficient $(r)$ & 0.9992 & 0.9999 & 0.9997 & 0.9995 & 0.9998 \\
\hline Quantification limit (mg/L) & 0.1 & 0.3 & 0.18 & 0.15 & 0.6 \\
\hline Detection limit (mg/L) & 0.04 & 0.1 & 0.06 & 0.05 & 0.2 \\
\hline
\end{tabular}

TABle 2: Precision of the method.

\begin{tabular}{|c|c|c|c|}
\hline \multirow{2}{*}{ Compound } & \multirow{2}{*}{$\begin{array}{c}\text { Concentration tested } \\
(\mathrm{mg} / \mathrm{L})\end{array}$} & \multicolumn{2}{|c|}{ Precision RSD (\%) } \\
\hline & & Intraday & Interday \\
\hline \multirow{3}{*}{ DEX sodium phosphate } & 1 & 1.31 & 1.74 \\
\hline & 20 & 0.72 & 0.95 \\
\hline & 40 & 0.45 & 0.71 \\
\hline \multirow{3}{*}{ OND hydrochloride } & 2 & 0.62 & 1.53 \\
\hline & 16 & 0.70 & 1.54 \\
\hline & 32 & 1.54 & 2.16 \\
\hline \multirow{3}{*}{ GRA hydrochloride } & 1.2 & 1.06 & 2.28 \\
\hline & 6 & 1.03 & 1.35 \\
\hline & 12 & 0.41 & 1.90 \\
\hline \multirow{3}{*}{ TRO hydrochloride } & 1 & 0.55 & 1.28 \\
\hline & 10 & 1.25 & 1.96 \\
\hline & 20 & 0.42 & 1.15 \\
\hline \multirow{3}{*}{ AZA hydrochloride } & 2 & 1.80 & 2.47 \\
\hline & 20 & 0.86 & 1.52 \\
\hline & 40 & 0.34 & 1.15 \\
\hline
\end{tabular}

hydrochloride; 2.0, 20.0, and 40.0 $\mu \mathrm{g} / \mathrm{mL}$ for AZA hydrochloride) with six determinations per concentration at the same day. Interday precision (6 days) was also estimated as the RSD calculated from three quality control samples in the same way. The calculated RSD values from repeated measurements were summarized in Table 2.

3.4. Accuracy. The accuracy of the method was demonstrated at three different concentration levels $(50-150 \%)$ by spiking a known quantity of DEX sodium phosphate, OND hydrochloride, GRA hydrochloride, TRO hydrochloride, and AZA hydrochloride standard drugs into infusion samples in triplicate. The results for accuracy of the method are given in Table 3. Recoveries of DEX sodium phosphate, OND hydrochloride, GRA hydrochloride, TRO hydrochloride, and AZA hydrochloride in infusion samples were between 98.0 and $102.0 \%$, indicating the good accuracy of the developed method.

3.5. Physicochemical Stability Study of the Infusion Samples. No precipitation or color change was observed in all of the infusion mixtures during the 48 hours storage period. The results of the HPLC analysis for each of the test drugs are presented in Figure 3. There was no loss of DEX sodium phosphate that occurred with any of the drugs over 48 hours stored at $25^{\circ} \mathrm{C}$. Similarly, little or no loss of OND hydrochloride, GRA hydrochloride, TRO hydrochloride, and AZA hydrochloride occurred over 48 hours. The average $\mathrm{pH}$ of the infusion mixtures stored at $25^{\circ} \mathrm{C}$ over 48 hours measurements are given in Table 4 . The $\mathrm{pH}$ of all infusions was considered insignificant over 48 hours. Based on the data presented herein, we believe that the mixtures of DEX sodium phosphate-OND hydrochloride; DEX sodium phosphate-GRA hydrochloride; DEX sodium phosphateTRO hydrochloride and AZA hydrochloride in normal saline were stable for up to 48 hours when stored in polyolefin bags protected from daylight at $25^{\circ} \mathrm{C}$. The satisfactory stability of the drugs in the mixtures makes it possible to prepare them in advance by licensed central intravenous additive services, which may be convenient in hospitals.

\section{Conclusions}

The developed HPLC-DAD method is simple, sensitive, specific, and adequate to the simultaneous quantification of DEX 
TABLE 3: Accuracy of the method.

\begin{tabular}{lccc}
\hline Compound & $\begin{array}{c}\text { Amount added } \\
(\mathrm{mg} / \mathrm{L})\end{array}$ & $\begin{array}{c}\text { Amount recovered } \\
(\mathrm{mean} \pm \mathrm{SD}, \mathrm{mg} / \mathrm{L})\end{array}$ & $\begin{array}{c}\text { \% recovery } \\
(\mathrm{mean} \pm \mathrm{SD}, n=3)\end{array}$ \\
\hline & 10 & $9.988 \pm 0.166$ & $99.88 \pm 1.66$ \\
DEX sodium phosphate & 20 & $19.897 \pm 0.526$ & $99.48 \pm 2.63$ \\
& 30 & $30.242 \pm 0.579$ & $100.81 \pm 1.93$ \\
OND hydrochloride & 8 & $7.878 \pm 0.142$ & $99.48 \pm 1.78$ \\
& 16 & $16.174 \pm 0.138$ & $100.09 \pm 0.86$ \\
GRA hydrochloride & 24 & $23.895 \pm 0.403$ & $99.56 \pm 1.68$ \\
& 3 & $3.764 \pm 0.021$ & $99.69 \pm 0.70$ \\
TRO hydrochloride & 6 & $6.013 \pm 0.062$ & $100.21 \pm 1.03$ \\
& 9 & $9.078 \pm 0.111$ & $100.87 \pm 1.24$ \\
AZA hydrochloride & 5 & $4.956 \pm 0.068$ & $9.13 \pm 1.36$ \\
& 10 & $9.876 \pm 0.166$ & $98.76 \pm 1.66$ \\
& 15 & $14.860 \pm 0.122$ & $99.06 \pm 0.81$ \\
& 10 & $10.018 \pm 0.129$ & $100.18 \pm 1.29$ \\
& 20 & $19.979 \pm 0.486$ & $99.89 \pm 2.43$ \\
\hline
\end{tabular}

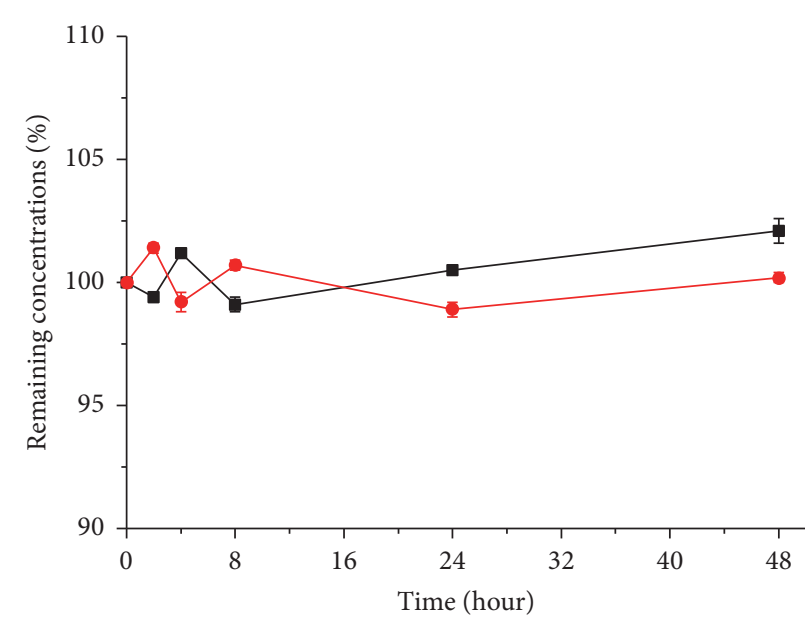

- Dexamethasone

- Ondansetron

(a)

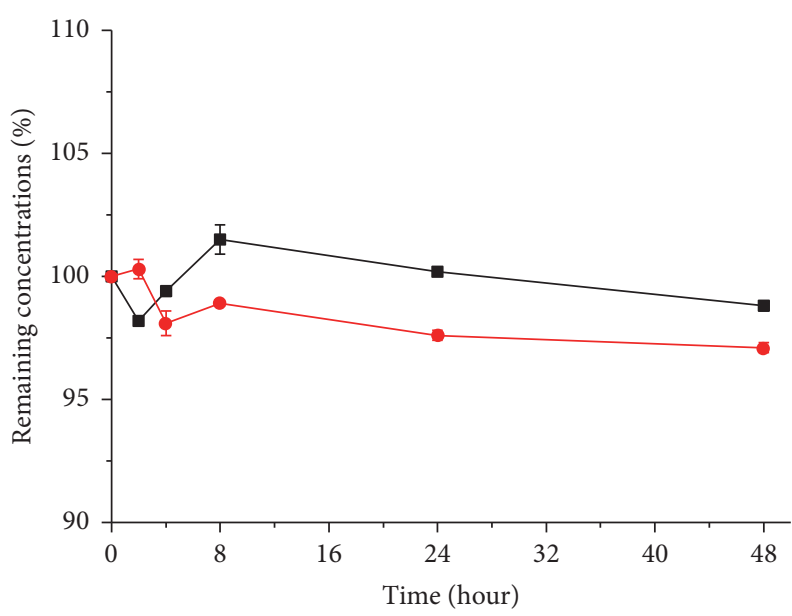

- Dexamethasone

- Tropisetron

(c)

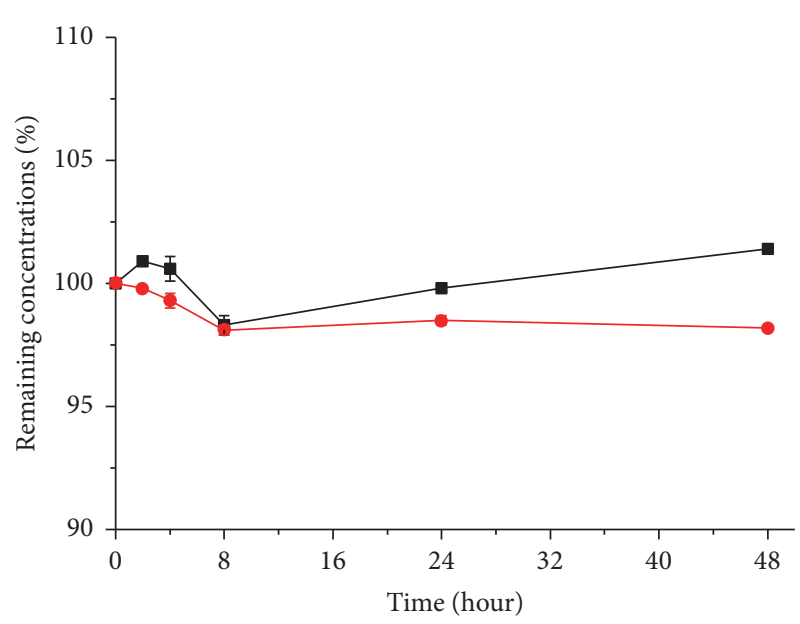

- Dexamethasone

- Granisetron

(b)

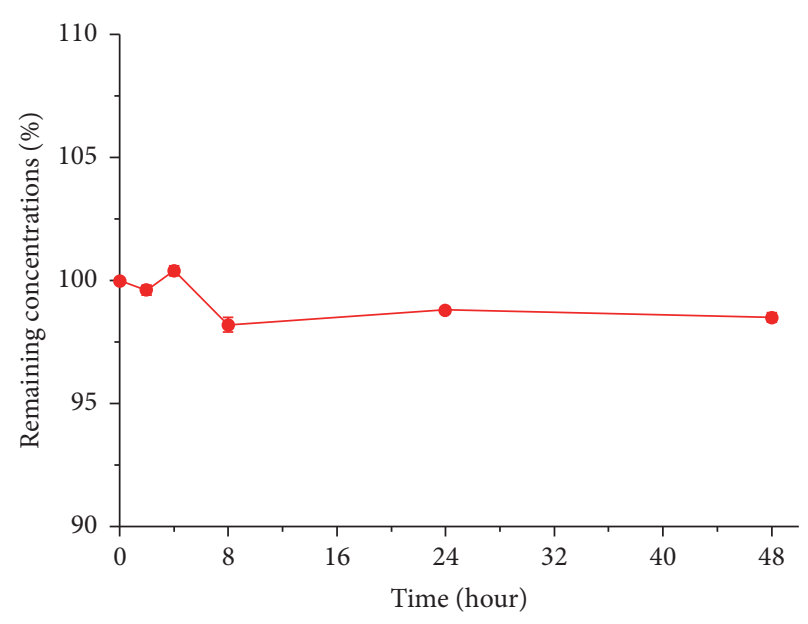

- Azasetron

FIGURE 3: Drug concentrations (mean \pm SD [\%]; $n=3$ ) of DEX-OND, DEX-GRA, DEX-TRO, and AZA in $0.9 \%$ sodium chloride injection over 48 hours at $25^{\circ} \mathrm{C}$. 
TABLE 4: $\mathrm{pH}$ values (mean $\pm \mathrm{SD} ; n=3$ ) of the infusion samples over 48 hours.

\begin{tabular}{|c|c|c|c|c|}
\hline \multirow{2}{*}{ Time (hours) } & \multicolumn{4}{|c|}{$\mathrm{pH}$ value } \\
\hline & $\mathrm{DEX}+\mathrm{OND}$ & DEX + GRA & DEX + TRO & AZA \\
\hline 0 & $5.65 \pm 0.01$ & $5.52 \pm 0.04$ & $6.42 \pm 0.02$ & $4.91 \pm 0.05$ \\
\hline 2 & $5.72 \pm 0.04$ & $5.43 \pm 0.02$ & $6.49 \pm 0.04$ & $4.85 \pm 0.02$ \\
\hline 4 & $5.77 \pm 0.03$ & $5.55 \pm 0.01$ & $6.51 \pm 0.04$ & $4.83 \pm 0.01$ \\
\hline 8 & $5.73 \pm 0.01$ & $5.57 \pm 0.01$ & $6.46 \pm 0.01$ & $4.86 \pm 0.06$ \\
\hline 24 & $5.62 \pm 0.02$ & $5.50 \pm 0.05$ & $6.55 \pm 0.02$ & $4.80 \pm 0.03$ \\
\hline 48 & $5.70 \pm 0.01$ & $5.58 \pm 0.02$ & $6.54 \pm 0.02$ & $4.83 \pm 0.02$ \\
\hline
\end{tabular}

sodium phosphate, OND hydrochloride, GRA hydrochloride, TRO hydrochloride, and AZA hydrochloride in infusion samples. The method was successfully applied to a study of the chemical stability of these infusion mixtures under $25^{\circ} \mathrm{C}$ for 48 hours. The method might also be suitable for application to other analytical problems, for example, quality control of pharmaceutical formulations or evaluating the chemical stability of referred drugs in mixtures for clinical use. The results of the stability study showed that mixtures of DEX sodium phosphate-OND hydrochloride; DEX sodium phosphate-GRA hydrochloride; DEX sodium phosphateTRO hydrochloride and AZA hydrochloride in normal saline in $0.9 \%$ sodium chloride injection when stored in polyolefin bags protected from daylight were chemically stable for 48 hours at $25^{\circ} \mathrm{C}$.

\section{Competing Interests}

The authors declare that there is no conflict of interests regarding the publication of this paper.

\section{Authors' Contributions}

Fu-chao Chen and Lin-hai Wang contributed equally to this work.

\section{Acknowledgments}

The authors gratefully acknowledge the financial supports for the research from Hubei Province Health and Family Planning Scientific Research project, China (no. WJ2015MB215), and Technology Key Program of Shiyan, China (no. 16Y66).

\section{References}

[1] E. Rosenblatt, L. M. Lev, and E. Robinson, "High-dose dexamethasone and high-dose metoclopramide versus high-dose dexamethasone and sulpiride in the management of cisplatininduced emesis," Oncology, vol. 45, no. 4, pp. 297-299, 1988.

[2] M. S. Aapro and D. S. Alberts, "Dexamethasone as an antiemetic in patients treated with cisplatin," New England Journal of Medicine, vol. 305, no. 9, p. 520, 1981.

[3] A. C. Tricco, C. Soobiah, E. Blondal et al., "Comparative efficacy of serotonin $\left(5-\mathrm{HT}_{3}\right)$ receptor antagonists in patients undergoing surgery: a systematic review and network metaanalysis," BMC Medicine, vol. 13, no. 1, article no. 136, 2015.
[4] G. McCracken, P. Houston, and G. Lefebvre, "Guideline for the management of postoperative nausea and vomiting," Journal of Obstetrics and Gynaecology Canada, vol. 30, no. 7, pp. 600-607, 2008.

[5] T. K. MacHu, "Therapeutics of $5-\mathrm{HT}_{3}$ receptor antagonists: current uses and future directions," Pharmacology and Therapeutics, vol. 130, no. 3, pp. 338-347, 2011.

[6] D. A. Perwitasari, H. Gelderblom, J. Atthobari et al., "Antiemetic drugs in oncology: pharmacology and individualization by pharmacogenetics," International Journal of Clinical Pharmacy, vol. 33, no. 1, pp. 33-43, 2011.

[7] S. Ithimakin, K. Runglodvatana, A. Nimmannit et al., "Randomized, double-blinded, placebo-controlled trial of ondansetron plus dexamethasone with or without metoclopramide as antiemetic prophylaxis in patients receiving high-dose cisplatin in medical practice," Supportive Care in Cancer, vol. 20, no. 4, pp. 849-855, 2012.

[8] M. Saito, K. Aogi, I. Sekine et al., "Palonosetron plus dexamethasone versus granisetron plus dexamethasone for prevention of nausea and vomiting during chemotherapy: a double-blind, double-dummy, randomised, comparative phase III trial," The Lancet Oncology, vol. 10, no. 2, pp. 115-124, 2009.

[9] D. T. T. Chua, J. S. T. Sham, D. L. W. Kwong et al., "Comparative efficacy of three $5-\mathrm{HT}_{3}$ antagonists (granisetron, ondansetron, and tropisetron) plus dexamethasone for the prevention of cisplatin-induced acute emesis: a randomized crossover study," American Journal of Clinical Oncology, vol. 23, no. 2, pp. 185-191, 2000.

[10] T. Hayakawa, M. Sato, M. Konaka et al., "Comparison of ramosetron and azasetron for prevention of acute and delayed cisplatin-induced emesis in lung cancer patients," Cancer \& Chemotherapy, vol. 33, no. 5, pp. 633-638, 2006.

[11] F.-C. Chen, J. Zhu, B. Li, F.-J. Yuan, and L.-H. Wang, "Stability of tramadol with three $5-\mathrm{HT}_{3}$ receptor antagonists in polyolefin bags for patient-controlled delivery systems," Drug Design, Development and Therapy, vol. 10, pp. 1869-1875, 2016.

[12] F. Bourdon, M. Lecoeur, P. Odou, C. Vaccher, and C. Foulon, "Complementarity of UV-PLS and HPLC for the simultaneous evaluation of antiemetic drugs," Talanta, vol. 120, pp. 274-282, 2014.

[13] C. Bougouin, C. Thelcide, F. Crespin-Maillard, C. Maillard, J. M. Kinowski, and M. Favier, "Compatibility of ondansetron hydrochloride and methylprednisolone sodium succinate in multilayer polyolefin containers," American Journal of HealthSystem Pharmacy, vol. 62, no. 19, pp. 2001-2005, 2005.

[14] S. Bauer, E. Strmer, R. Kaiser, P.-B. Tremblay, J. Brockmller, and I. Roots, "Simultaneous determination of ondansetron and 
tropisetron in human plasma using HPLC with UV detection," Biomedical Chromatography, vol. 16, no. 3, pp. 187-190, 2002.

[15] H. AlAani and Y. Alnukkary, "Stability-indicating HPLC method for simultaneous determination of chloramphenicol, dexamethasone sodium phosphate and tetrahydrozoline hydrochloride in ophthalmic solution," Advanced Pharmaceutical Bulletin, vol. 6, no. 1, pp. 137-141, 2016.

[16] V. D. Hoang, N. T. Hue, N. H. Tho, and H. M. T. Nguyen, "Simultaneous determination of chloramphenicol, dexamethasone and naphazoline in ternary and quaternary mixtures by RP-HPLC, derivative and wavelet transforms of UV ratio spectra," Spectrochimica Acta-Part A: Molecular \& Biomolecular Spectroscopy, vol. 139, pp. 20-27, 2015.

[17] A. A. Heda, J. M. Kathiriya, D. D. Gadade, and P. K. Puranik, "Development and validation of RP-HPLC method for simultaneous determination of granisetron and dexamethasone," Indian Journal of Pharmaceutical Sciences, vol. 73, no. 6, pp. 696-699, 2011.

[18] S. Negro, A. Salama, Y. Sánchez, M. L. Azuara, and E. Barcia, "Compatibility and stability of tramadol and dexamethasone in solution and its use in terminally ill patients," Journal of Clinical Pharmacy \& Therapeutics, vol. 32, no. 5, pp. 441-444, 2007.

[19] F. Pinguet, P. Rouanet, P. Martel, M. Fabbro, D. Salabert, and C. Astre, "Compatibility and stability of granisetron, dexamethasone, and methylprednisolone in injectable solutions," Journal of Pharmaceutical Sciences, vol. 84, no. 2, pp. 267-268, 1995.

[20] R. L. Hagan, M. S. Mallett, and J. L. Fox, "Stability of ondansetron hydrochloride and dexamethasone sodium phosphate in infusion bags and syringes for 32 days," American Journal of Health-System Pharmacy, vol. 53, no. 12, pp. 1431-1435, 1996.

[21] C. R. Anderson, Z. Halford, and M. MacKay, "Stability of diphenhydramine hydrochloride, lorazepam, and dexamethasone sodium phosphate in $0.9 \%$ sodium chloride stored in polypropylene syringes," International Journal of Pharmaceutical Compounding, vol. 19, no. 4, pp. 344-347, 2015.

[22] A. Chin, Y. S. K. Moon, K. C. Chung, and M. A. Gill, "Stability of granisetron hydrochloride with dexamethasone sodium phosphate for 14 days," American Journal of HealthSystem Pharmacy, vol. 53, no. 10, pp. 1174-1176, 1996.

[23] S. E. Walker and S. Law, "Stability and compatibility of granisetron alone and combination with dexamethasone in $0.9 \%$ sodium chloride and $5 \%$ dextrose in water solutions," Canadian Journal of Hospital Pharmacy, vol. 55, no. 1, pp. 2738, 2002.

[24] S. Y. Um, S. W. Chae, H. J. Park, M. W. Chung, S. O. Choi, and H. J. Lee, "Simple determination of azasetron in rat plasma by column-switching high-performance liquid chromatography," Journal of Separation Science, vol. 33, no. 23-24, pp. 3638-3643, 2010.

[25] F.-C. Chen, H. Xiong, H.-M. Liu, B.-X. Fang, and P. Li, "Compatibility of butorphanol with granisetron in $0.9 \%$ sodium chloride injection packaged in glass bottles or polyolefin bags," American Journal of Health-System Pharmacy, vol. 72, no. 16, pp. 1374-1378, 2015.

[26] T. G. Venkateshwaran, D. T. King, and J. T. Stewart, "HPLC determination of a metoclopramide and ondansetron mixture in $0.9 \%$ sodium chloride injection," Journal of Liquid Chromatography, vol. 18, no. 1, pp. 117-126, 1995.

[27] R. P. Shirish, L. J. Patel, P. T. Yogeshvar, and D. P. Nimesh, "Development and validation of analytical method for the determination of rabeprazole and ondansetron in pharmaceutical dosage form by reversed-phase HPLC," International Journal of Chemtech Research Coden, vol. 2, no. 3, pp. 1531-1536, 2010.

[28] Z. Dedania, R. Dedania, V. Karkhanis et al., "RP-HPLC method for simultaneous estimation of omeprazole and ondansetron in combined dosage forms," Asian Journal of Research in Chemistry, vol. 2, no. 2, pp. 108-111, 2009.

[29] A. Suneetha and T. Chandana Priya, "RP-HPLC method for simultaneous estimation of paracetamol and ondansetron in bulk \& oral suspension," Journal of Pharmaceutical Research, vol. 13, no. 4, pp. 106-110, 2014.

[30] B. M. Amarnath and M. Srinivas, "Method development and validation of RP-HPLC method for the simultaneous estimation of pantoprazole and ondansetron hydrochloride in bulk and in a synthetic mixture," International Journal of PharmTech Research, vol. 6, no. 6, pp. 1794-1802, 2014.

[31] D. T. King and J. T. Stewart, "HPLC determination of dacarbazine, doxorubicin, and ondansetron mixture in 5\% dextrose injection on underivatized silica with an aqueous-organic mobile phase," Journal of Liquid Chromatography \& Related Technologies, vol. 16, no. 11, pp. 2309-2323, 1993. 

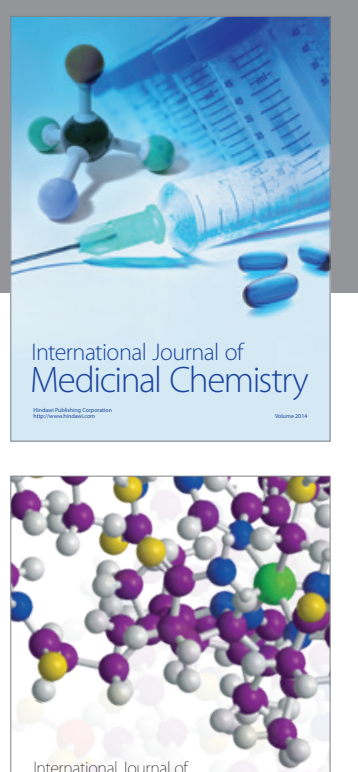

Carbohydrate Chemistry

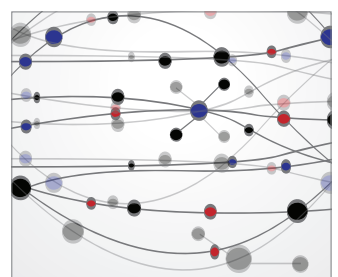

The Scientific World Journal
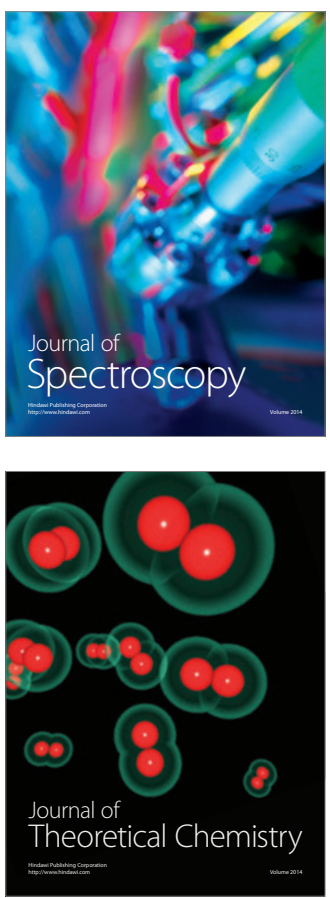
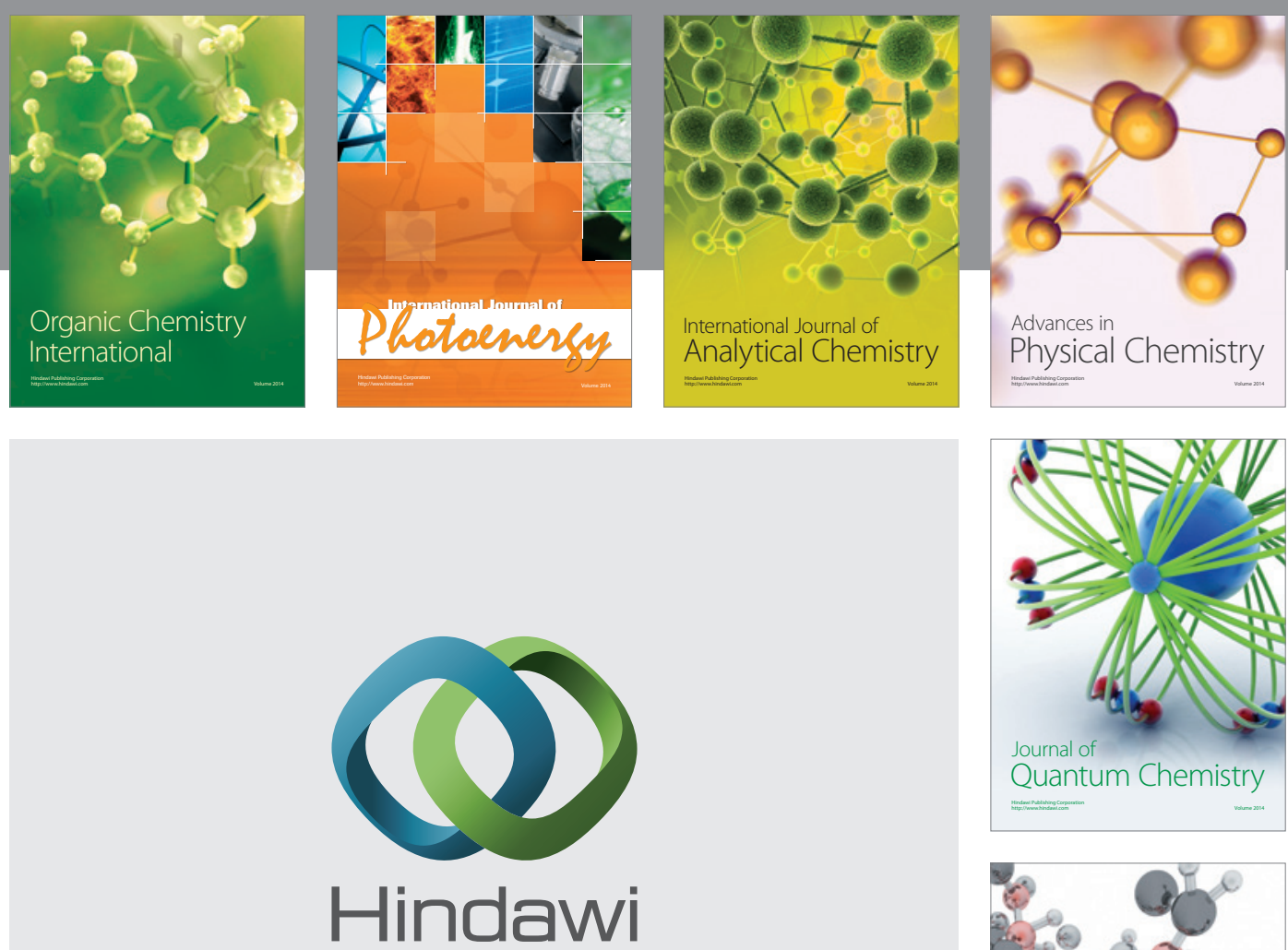

Submit your manuscripts at

https://www.hindawi.com

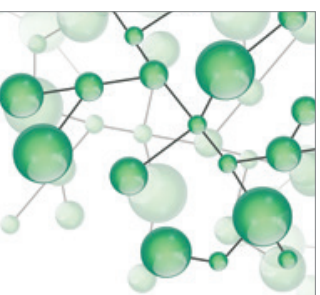

International Journal of

Inorganic Chemistry
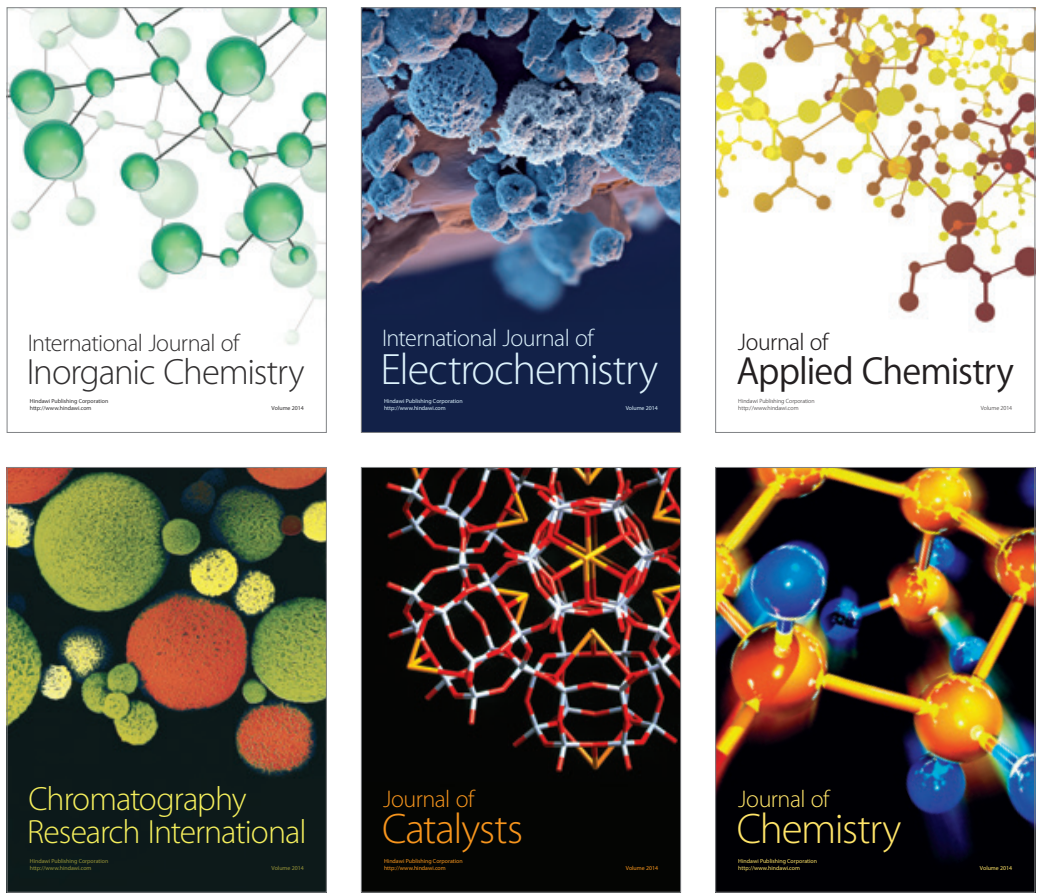

Journal of

Applied Chemistry
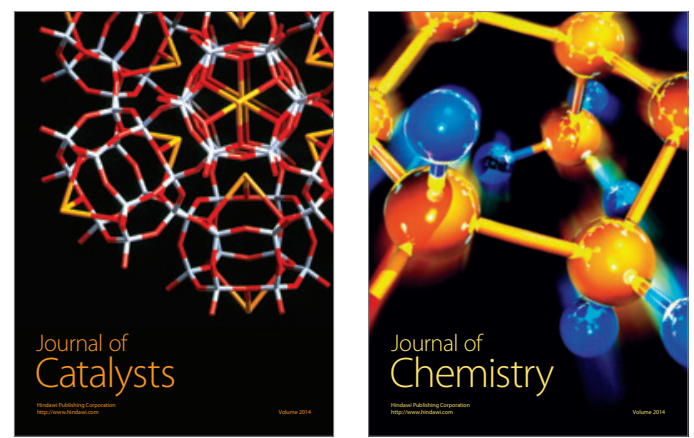
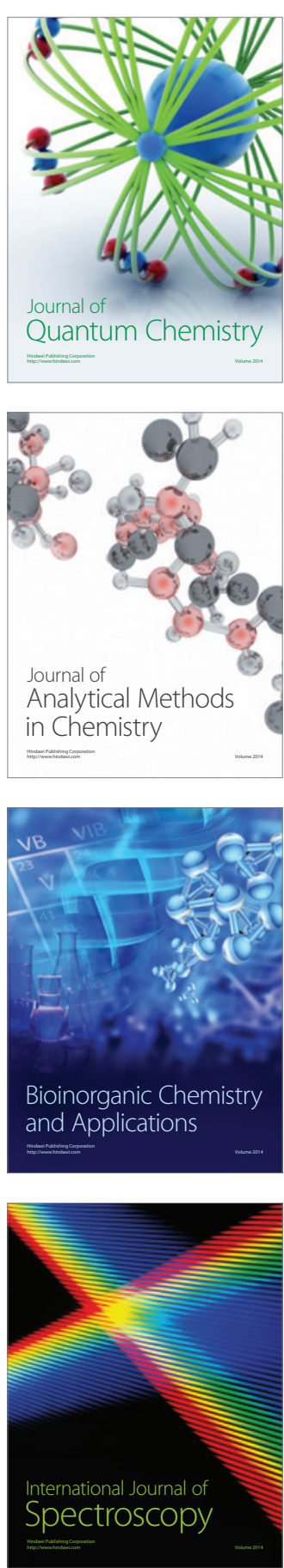